MOREIRA, A.J.C. et al. Relato de caso: Síndrome ascítica em frangos de corte durante o outono na região noroeste do Estado de São Paulo. PUBVET, Londrina, V. 5, N. 34, Ed. 181, Art. 1222, 2011.

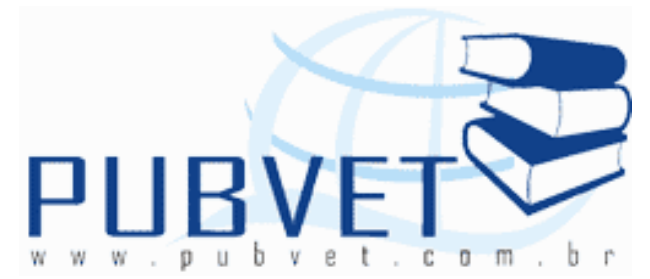

PUBVET, Publicações em Medicina Veterinária e Zootecnia.

\title{
Relato de caso: Síndrome ascítica em frangos de corte durante o outono na região noroeste do Estado de São Paulo.
}

\author{
Alício José Corbucci Moreira ${ }^{1}$, Cláudia Mitidiero Stachissini Arcain², Leandro \\ Barradas Pereira ${ }^{3}$, Daniel Fernandes da Silva ${ }^{4}$
}

1 Médico veterinário, Especialista em produção animal, Auxiliar Docente da ETEC de Andradina (Centro Paula Souza), E-mail: aliciomedvet@ig.com.br

2 Médica Veterinária, Mestre em produção animal, Docente da ETEC de Andradina (Centro Paula Souza), E-mail: claudiamsarcain@hotmail.com

3. Engenheiro Agrônomo, Doutorando em Agronomia. Docente da ETEC de Andradina (Centro Paula Souza), Email: Ibpereira25@hotmail.com

4. Técnico em Agropecuária da ETEC de Andradina (Centro Paula Souza) Email: danielfernandes11@ig.com.br

\section{Resumo}

O presente trabalho objetiva relatar os casos de síndrome ascítica em frangos de corte ocorridos na Escola Técnica (ETEC) de Andradina, localizada na região noroeste do Estado de São Paulo, com intuito de contribuir com a melhor compreensão do distúrbio tão comum na avicultura moderna, principalmente nas estações do ano onde ocorre acentuada variação da temperatura, aumento da intensidade de ventos e consequente mortalidade dos lotes. No presente relato foram comuns achados clínicos de aves prostradas, com penas eriçadas, distensão abdominal, coloração cianótica e retardo de crescimento. Já em 
MOREIRA, A.J.C. et al. Relato de caso: Síndrome ascítica em frangos de corte durante o outono na região noroeste do Estado de São Paulo. PUBVET, Londrina, V. 5, N. 34, Ed. 181, Art. 1222, 2011.

relação às necropsias os achados mais comuns foram: liquido amarelado com material gelatinoso, fígado congesto e irregular e dilatação cardíaca direita. A síndrome foi responsável por $81,81 \%$ da mortalidade total ocorrida no lote.

Palavras-chave: Frangos de corte; síndrome metabólica; ambiência; mortalidade.

\title{
Case report: Ascitic syndrome in broiler chicken during the autumn in the northwest region of São Paulo
}

\begin{abstract}
This research aims at reporting the cases of Ascitic Syndrome in chickens at Techinician School (ETEC) - Andradina, located in the northwest of the state of São Paulo, to better understand such disorder which is so common in modern chicken raising, mainly throughout the seasons of the year when there is great temperature variation, wind increase and consequently, death of the lots. In this report, there were findings of prostrated birds, bristling legs, abdominal distention, bluish color and growth impairment. In relation to the necropsies, the most common findings were: yellowish liquid with jelly material, congested and irregular liver, right cardiac dilation. The syndrome was responsible for $81.81 \%$ of mortality in the lot.
\end{abstract}

Keywords: broiler chicken; metabolic syndrome; ambiance; mortality

\section{Introdução}

A avicultura atual vem se destacando como fonte de proteína animal de baixo custo, esses resultados se tornaram possíveis através de pesquisas e incremento genético a qual os frangos de corte foram submetidos. Outro fator fundamental na evolução avícola é o avanço alcançado pela indústria de formulação de rações, sendo grande parte deste mérito associado à introdução da informática e seu crescimento como ferramenta para cálculos matemáticos, reduzindo a margem de erro comumente associada a desvios na composição das rações. 
MOREIRA, A.J.C. et al. Relato de caso: Síndrome ascítica em frangos de corte durante o outono na região noroeste do Estado de São Paulo. PUBVET, Londrina, V. 5, N. 34, Ed. 181, Art. 1222, 2011.

Com base nas mudanças e necessidades de mercado expostas anteriormente fica claro a pressão de seleção a qual os frangos de corte foram submetidos visando à máxima produção. Desta forma, foram desenvolvidos animais musculosos, altamente precoces e de apetite voraz, sendo suas características fenotípicas moldadas de acordo com a vontade e necessidade dos melhoradores, não se atentando e/ou assumindo os riscos metabólicos aos quais os animais estão sujeitos.

Dentre os transtornos considerados de origem metabólica, a síndrome ascítica ganha destaque por contribuir com prejuízos diretos e indiretos no campo e nas indústrias processadoras de carne, pois em algumas épocas do ano (outono/inverno) alcança números importantes de mortalidade, atraso de crescimento e condenações parciais e/ou totais de carcaça durante o abate.

Com base nas necessidades de divulgação e conhecimentos referentes aos casos de transtornos de origem metabólica, o presente trabalho tem como objetivo contribuir com o melhor entendimento dos casos de mortalidade oriundos de ascíte em frangos de corte, criados sabidamente em estações consideradas críticas (outono/inverno), sob condições de ambiência similares às encontradas em pequenas propriedades familiares, a fim de detectar sua resistência às intempéries climáticas e consequente manifestação típica de quadros ascíticos.

\section{Descrição dos casos}

O lote de 120 pintos de um dia (misto de fêmeas e machos) foram alojados em galpão com 3,2 m de largura e $10 \mathrm{~m}$ de comprimento, coberto com telhamento de zinco, equipado com cortinas e protegidos por arborização para melhoria da ambiência no galpão. No telhado foi instalado sistema de gotejamento de água com a finalidade de diminuir o estresse climático; já no interior do galpão foram instalados bebedouros manuais, tipo copo de pressão, durante a primeira semana de vida e bebedouro pendular no restante do ciclo. Para proteção térmica dos pintos durante as duas primeiras semanas foi utilizada campânula de aquecimento e circulo de proteção, sendo o seu raio de 
MOREIRA, A.J.C. et al. Relato de caso: Síndrome ascítica em frangos de corte durante o outono na região noroeste do Estado de São Paulo. PUBVET, Londrina, V. 5, N. 34, Ed. 181, Art. 1222, 2011.

alcance aumentado conforme o crescimento do lote. Também foi fornecido complexo de vitaminas para todos os animais através da água durante os primeiros dias com a finalidade de restabelecer boas condições fisiológicas perdidas durante o manejo e transporte nos primeiros dias de vida.

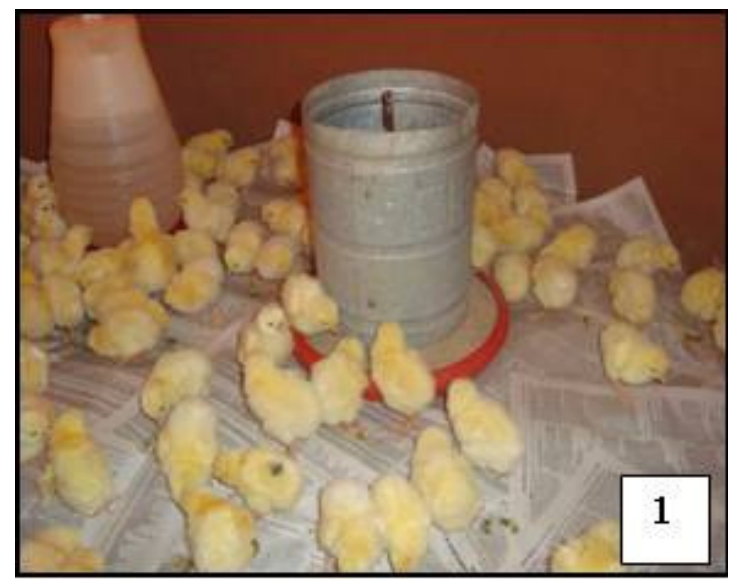

Foto1. Recepção e acomodação do lote em circulo de proteção pré-aquecido.

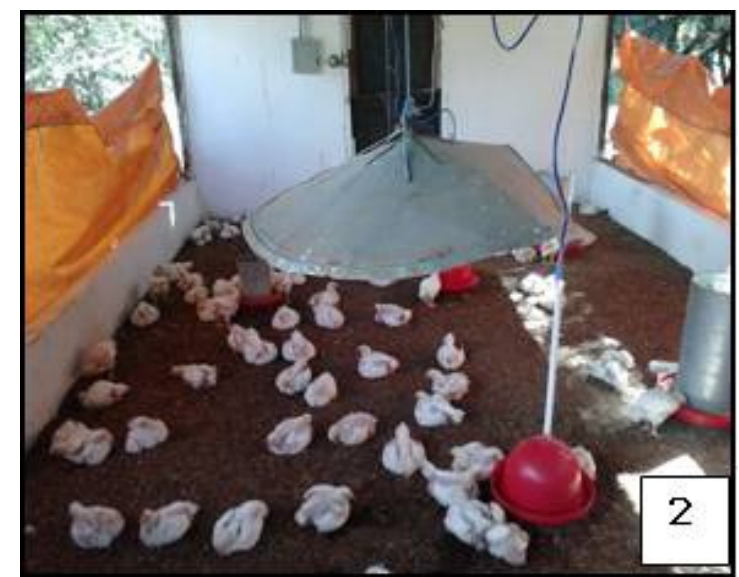

Foto 2. Lote ocupando todo o galpão aos 21 dias de idade após a retirada do circulo de proteção.

A ração utilizada foi dividida em F1 (fase inicial - do $1^{\circ}$ ao $21^{\circ}$ dia) e F2 (fase final - do $22^{\circ}$ dia até abate) com composição demonstrada na tabela 1. A ração foi fornecida a vontade durante todo o ciclo do lote, com posterior abate das aves aos 42(quarenta e dois) dias de idade, e obtenção de carcaça com peso médio de $2,56 \mathrm{~kg}$.

A mortalidade teve início na segunda semana após acomodação do lote, se estendendo até o final da quarta semana, atingindo total de 11 aves (9,16\% do lote). Todas as aves mortas foram avaliadas e passaram por necropsia para confirmação da causa da morte, sendo 9 aves $(81,81 \%$ da mortalidade total) diagnosticadas como síndrome ascítica. As demais mortes (2 aves, $18,18 \%$ da mortalidade total) foram consideradas como desconhecidas sendo que em um dos casos foi sugestivo de morte súbita, pois a pessoa responsável por alimentar as aves relatou um debater de asas e logo em seguida a morte em decúbito dorsal com pernas esticadas e asas e cristas arroxeadas. 
MOREIRA, A.J.C. et al. Relato de caso: Síndrome ascítica em frangos de corte durante o outono na região noroeste do Estado de São Paulo. PUBVET, Londrina, V. 5, N. 34, Ed. 181, Art. 1222, 2011.

Tabela 1. Composição da ração utilizada para os frangos de corte nas fases de criação inicial e final.

\begin{tabular}{lcc}
\hline \hline Níveis de garantia & Fase inicial (F1) & Fase final (F2) \\
\hline Umidade (máx.) & $13 \%$ & $13 \%$ \\
Proteína Bruta (mín.) & $16 \%$ & $13 \%$ \\
Extrato Etéreo (mín.) & $2 \%$ & $2 \%$ \\
Matéria Fibrosa (máx.) & $7,5 \%$ & $8 \%$ \\
Matéria Mineral (máx.) & $10 \%$ & $15 \%$ \\
Cálcio (máx.) & $2 \%$ & $1,8 \%$ \\
Fósforo (min) & $0,6 \%$ & $0,4 \%$ \\
\hline \hline
\end{tabular}

Durante exame clinico das aves os achados mais comuns foram penas eriçadas, e coloração cianótica nas asas, pernas e cristas. As aves acometidas por ascíte também se destacavam do lote pelo desenvolvimento abaixo da média, como é possível visualizar na foto 3.

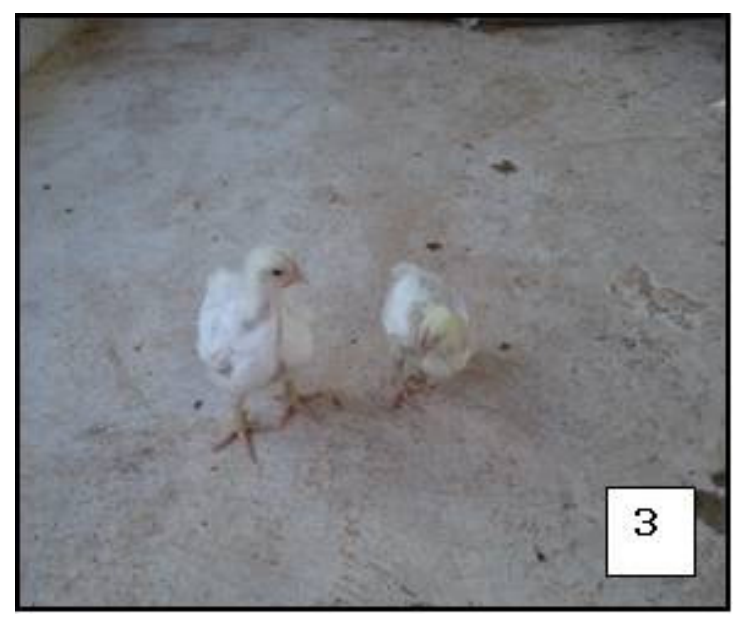

Foto 3. A esquerda ave fisiologicamente bem e a direita ave prostrada com retardo de crescimento.

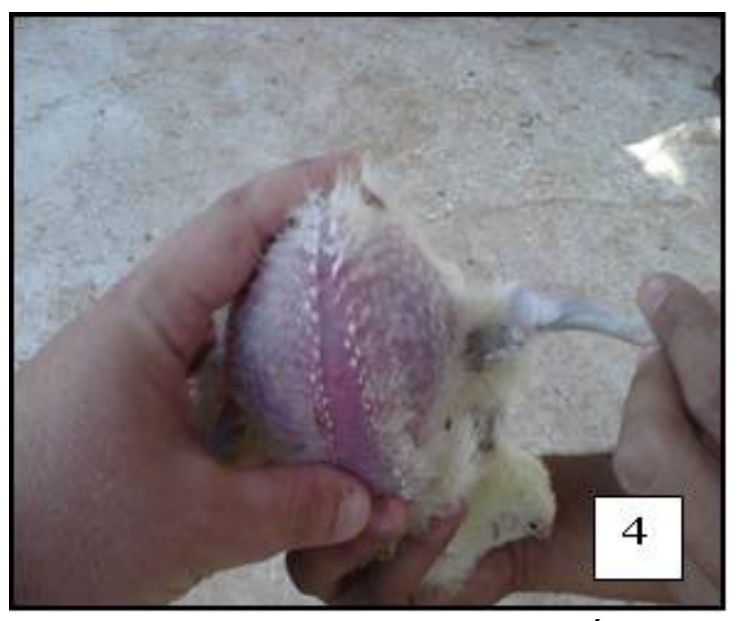

Foto 4. Pernas e asas cianóticas e aumento do volume abdominal. 
MOREIRA, A.J.C. et al. Relato de caso: Síndrome ascítica em frangos de corte durante o outono na região noroeste do Estado de São Paulo. PUBVET, Londrina, V. 5, N. 34, Ed. 181, Art. 1222, 2011.

Após avaliação clínica, as aves mortas foram encaminhadas para necropsia, onde foi realizada a incisão da pele resultando em achados expressivos, como aumento de volume abdominal característico em quadros de ascíte. No momento da incisão abdominal houve extravasamento de líquido ascítico em grande quantidade em algumas aves e em menor quantidade em outras, porém em todos os casos a coloração e aspecto remetiam claramente a confirmação do diagnóstico.

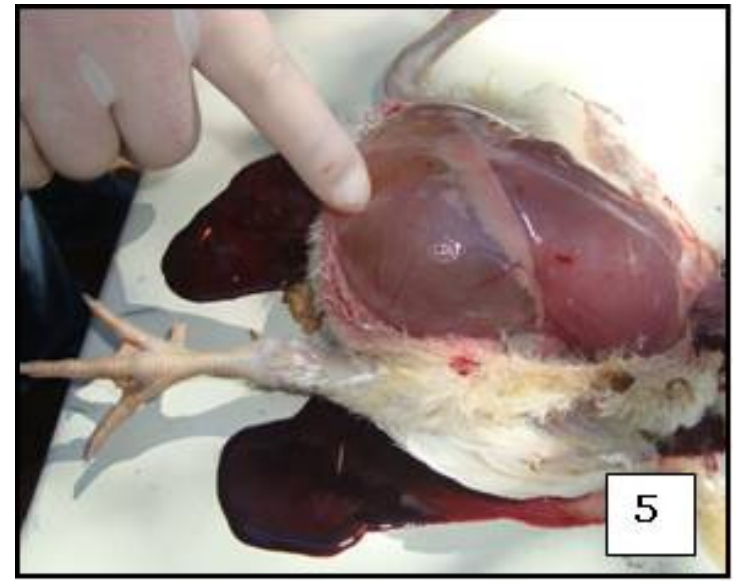

Foto 5. Cavidade abdominal repleta de líquido ascítico.

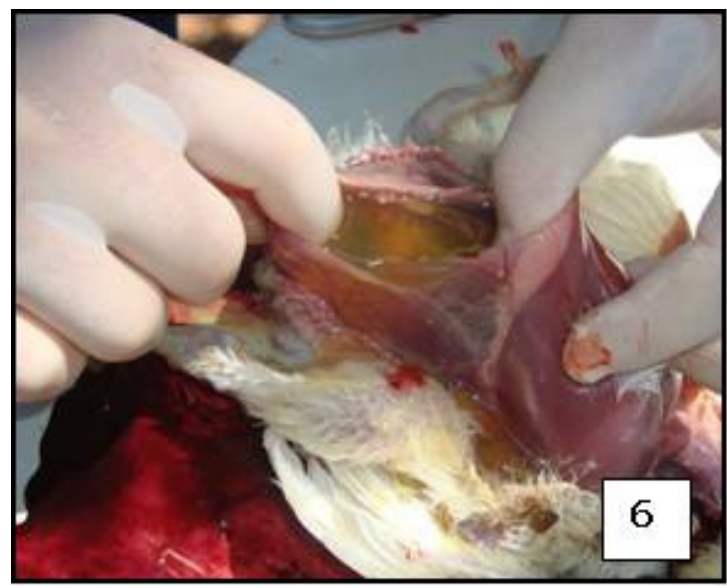

Foto 6. Liquido abdominal com coloração característica.

Outro achado de importância verificado foi à coloração do fígado e tamanho do coração, que em todas as necropsias realizadas apresentaram algum tipo de alteração. Quanto ao fígado comumente foi observado aumento de volume e coloração escura com contornos variáveis, já o coração apresentava dilatação cardíaca direita, com parede flácida e volume total maior que o normal. É importante ressaltar que todas as necropsias realizadas foram conduzidas minutos após a morte e em alguns casos os animais foram sacrificados para evitar sofrimento excessivo e alterações post mortem indesejáveis. 
MOREIRA, A.J.C. et al. Relato de caso: Síndrome ascítica em frangos de corte durante o outono na região noroeste do Estado de São Paulo. PUBVET, Londrina, V. 5, N. 34, Ed. 181, Art. 1222, 2011.

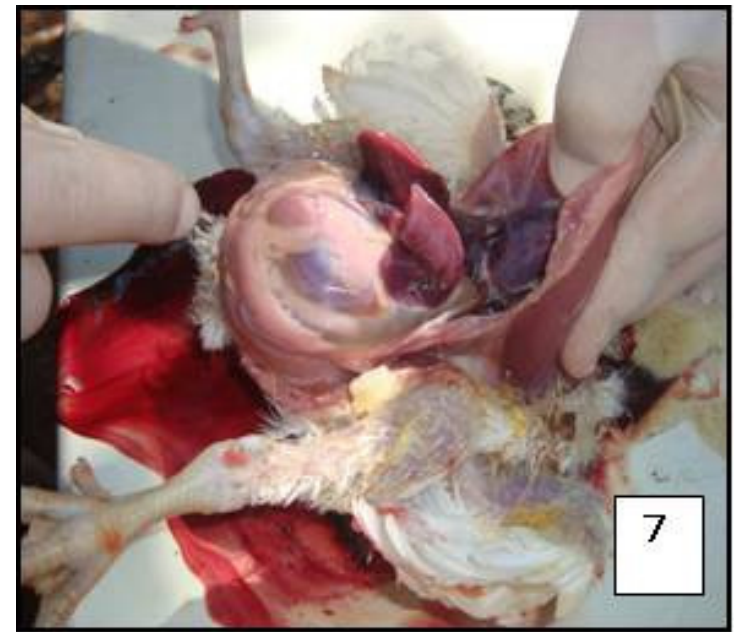

Foto 7. Fígado com contorno irregular.

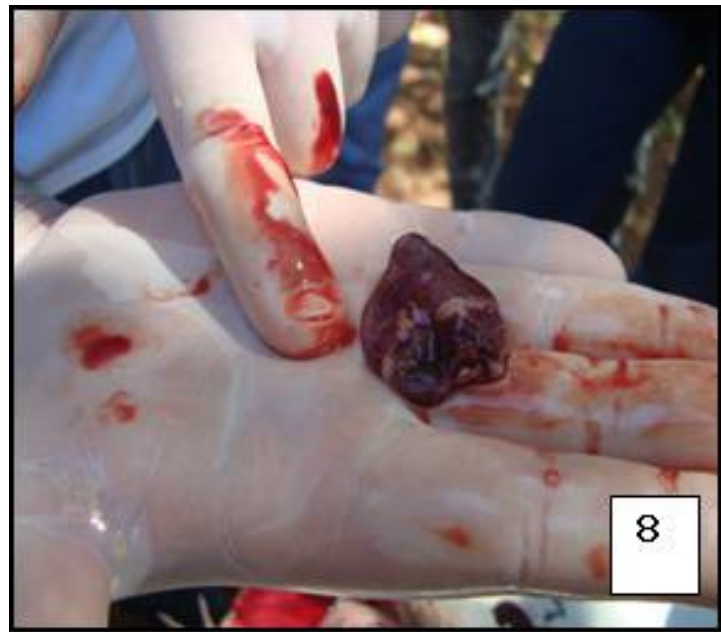

Foto 8. Dilatação cardíaca direita e paredes distendidas.

Em relação ao sangue dos animais submetidos à necropsia foi comumente observada uma coloração escurecida. É impossível sem a realização de um hematócrito afirmar que o sangue dos animais apresentava qualquer tipo de alteração, mas a priori toda ave acometida por síndrome ascíte tende a uma deficiência de oxigenação dos tecidos e aumento da viscosidade sanguínea, resultando em uma coloração alterada.

Mesmo com os distúrbios severos foi evidenciado que os animais continuavam se alimentando, pois papo e moela continham quantidade razoável de ração, indicando diminuição da ingestão de alimento, mas não suspensão total da ingestão, levando a considerar que apesar do retardo de crescimento, alguns frangos acometidos por ascíte teriam conseguido chegar a idade de abate com provável caquexia não fosse a severidade dos casos, agravados pela oscilação de temperatura a qual foram expostos durante as semanas mais críticas.

\section{Discussão}

Muitos são os fatores desencadeadores da síndrome ascítica e demais transtornos metabólicos, ou seja, geralmente é considerado um distúrbio multifatorial (MENDES, 2006). A perda da homeostase ou quando a ave consegue mantê-la à custa de muito esforço, independente da causa 
MOREIRA, A.J.C. et al. Relato de caso: Síndrome ascítica em frangos de corte durante o outono na região noroeste do Estado de São Paulo. PUBVET, Londrina, V. 5, N. 34, Ed. 181, Art. 1222, 2011.

(ambiência, seleção genética e/ou alimentar) torna os animais susceptíveis a alterações fisiológicas sendo claramente um fator fulminante para desencadeamento dos casos de transtornos metabólicos (FURLAN; MACARI; COSTA, s/d).

Segundo Nakamura et al., (1999), Jaenisch et al., (2001) estas alterações podem levar a necrose hepática originária do acúmulo de sangue desoxigenado no fígado, como resultante da estagnação do retorno venoso, decorrente da insuficiência cardíaca congestiva direita, elevando a pressão na veia porta e proporcionando o extravasamento de líquido do interior do vaso para a cavidade abdominal, surgindo o quadro de síndrome ascítica.

Outro ponto chave abordado pelo trabalho foi em relação às oscilações climáticas a qual as aves foram expostas durante o período de criação (outono), onde durante o dia as temperaturas se elevavam e durante a noite abaixavam drasticamente, sendo considerado como gatilho desencadeador de transtornos metabólicos, já que a faixa de conforto para frangos de corte encontra-se entre 24 e $25^{\circ} \mathrm{C}$ (FONSECA et al., 2010; COX, 2008).

Quanto à alimentação, a mesma foi fornecida a vontade sem restrições em todas as fases de criação. Esta situação segundo Figueiredo (s/d), pode agravar os casos de transtornos metabólicos, pois as aves selecionadas atualmente consomem acima das exigências metabólicas.

Brito e Carrer (2006) corroboram adicionando que a seleção genética leva em consideração a tríade do máximo desempenho zootécnico, ou seja, espera-se que sejam abatidas em períodos cada vez mais precoces, consumindo o mínimo de ração e com o peso corporal mais elevado possível, onde os efeitos são tão expressivos que possibilitaram ao frango crescer mais de 50 (cinquenta) vezes o seu peso de nascimento em apenas 42 (quarenta e dois) dias. Esta problemática segundo Pickett (2004) é comumente observada na produção de frangos de corte, onde devido ao crescimento acelerado seus ossos e coração se tornam frequentemente incapazes de suportar o corpo super desenvolvido. 
MOREIRA, A.J.C. et al. Relato de caso: Síndrome ascítica em frangos de corte durante o outono na região noroeste do Estado de São Paulo. PUBVET, Londrina, V. 5, N. 34, Ed. 181, Art. 1222, 2011.

Abreu et al., (1998) também evidenciam que o consumo voluntário de ração aumenta nos meses mais frios do ano, sendo considerado como um fator acelerador do crescimento, evidenciando possível relação de consumo alimentar, ganho de peso e estação do ano na incidência de mortes por ascíte. Alguns autores como Vieites et al., (s/d) sugerem como parte da evolução dos casos ascíticos a visualização inicial da síndrome da morte súbita, ao passo que as aves conseguem atravessar o período crítico de insuficiência cardíaca, tendem a cronicidade do caso, visualizado posteriormente como ascíte.

\section{Conclusão}

É evidente que estudos mais profundos do tema devem ser realizados, mas com base nos achados no estudo de caso foi significativa a contribuição climática para os casos de síndrome ascítica, pois resultou em aumento substancial na mortalidade. Outra conclusão importante foi em relação ao período de mortalidade por ascíte, restringindo-se entre a segunda e quarta semana de criação.

Durante as necropsias o coração dilatado (lado direito), região abdominal distendida, líquido amarelado com material gelatinoso, e fígado com contornos irregulares foram achados constantes, levando a considerar o diagnóstico como síndrome ascítica.

\section{Referências}

ABREU et. al. Morte Súbita e Ascite em Frangos de Corte Criados em Diferentes
Sistemas
de www.cnpsa.embrapa.br/down.php?tipo=publicacoes\&cod... Acesso em: 12/08/2010.

BRITO, A. B., CARRER, S. Problemas de pernas em frangos de corte, Poli-nutri Alimentos, Artigos técnicos, 2006.. Disponível em: www.polinutri.com.br Acesso em: 15/09/2010.

COX, B. Ascites in broiler chickens. Canadian Poultry Consultants, 2008.

FIGUEIREDO, E.A.P, Limites Fisiológicos do Melhoramento Genético de Aves: Teoria e Prática. XXXV Reunião Anual da Sociedade Brasileira de Zootecnia - Simpósios. Disponível em: www.cnpsa.embrapa.br/down.php?tipo=publicacoes\&cod... Acesso em: 10/09/2010. 
FONSECA, R.A. et al. Avaliação de Linhagens de Aves de Corte Tipo Caipira Submetidas ao Bioclima do Litoral do Paraná. 2010. Disponível em: < www.cescage.edu.br/publicacoes/scientiarural>. Acesso em: 10/09/2010.

FURLAN, R. L., MACARI, M., COSTA M.J.R.P. Bem-Estar das Aves e Suas Implicações sobre o Desenvolvimento e Produção. Disponível em: < www.ergomix.com.br $>$. Acesso em: $12 / 09 / 2010$

JAENISCH, F. R.F. et al. Síndrome da Hipertensão Pulmonar: a Ascite em Frangos de Corte. Circular técnica 27. Ministério da Agricultura, Pecuária e Abastecimento 2001 Disponível em: < www.ns.cnpsa.embrapa.br/down.php?tipo=publicacoes\&cod publicacao...> Acesso em: $12 / 08 / 2010$

MENDES, A.A. Doenças metabólicas de frangos de corte. In: ANDREATTI FILHO, R.L. Saúde Aviária e Doenças. São Paulo: Roca, 2006.

NAKAMURA et al. Comparative pathology of heart and liver lesions of broiler chicken that died of ascites, heart failure e others. Avian Dis., v. 43, n.3, p. 526-532, 1999.

PICKETT, H. Criação industrial de animais. Compassion in World Farming Trust. 2004. Disponível em: < www.ciwf.org >. Acesso em: 12/08/2010.

VIEITES, F. M. et al. Síndrome Ascítica em Produção de Frangos de Corte de Alto Potencial Genético. Disponível em: $<$ www.abz.org.br/files.php?file=S...Asc...Frangos... $>$ Acesso em: 25/08/2010. 